\title{
Bayesian Simple Step-Stress Acceleration Life Testing Plan under Progressive Type-I Right Censoring for Exponential Life Distribution
}

\author{
Saleem Z. Ramadan (Corresponding author) \\ Department of Mechanical and Industrial Engineering \\ Applied Science University \\ Shafa Badran 11931, Amman, Jordan \\ E-mail: s_ramadan@asu.edu.jo \\ Khaled Z. Ramadan \\ Department of Civil Engineering \\ Applied Science University \\ Shafa Badran 11931, Amman, Jordan
}

Received: February 1, 2012

Accepted: February 9, 2012 Published: March 1, 2012

doi:10.5539/mas.v6n3p91

URL: http://dx.doi.org/10.5539/mas.v6n3p91

\begin{abstract}
This paper discusses the design of the optimal SSALT plan using Bayesian approach and progressive Type-I right censoring for an exponential life distribution under large sample size and small censoring proportion. The cumulative exposure model and the exponential life distribution in both steps are assumed. The progressive Type-I right censoring can reduce the cost of the test. This reduction, unfortunately, comes on the expense of reducing the precision of the test. The optimal test parameters, the stress changing time and the first step stress, are obtained by minimizing the expected variance of the life for the $p^{\text {th }}$ percentile using Bayesian approach. A comparison between conventional Type-I and progressive Type-I right censoring is also provided. The results showed that progressive Type-I right censoring is recommended when strong prior information for the model parameters is used as the test precision becomes less sensitive to the censoring proportion.
\end{abstract}

Keywords: Reliability, Accelerated life testing, Cumulative exposure model, Bayesian estimation, Progressive Type-I censoring

\section{Introduction}

Traditional life tests are conducted to evaluate product reliability. In general, certain number of samples is tested under normal operating conditions to infer the parameters of the life distribution for the product. Because most products have high reliability these days, traditional life tests will have long durations which renders them of no practical use. One way to overcome this problem is by using accelerated life tests (ALTs) in which the failures are induced in the samples by subjecting them to operating conditions that are more severe than normal. Interested readers can refer to Meeker and Escobar (1998) and Nelson (1990).

Accelerated step-stress life testing are considered as an extension for ALT in which some samples may be subjected to more than one stress level, and consequently, this increases the flexibility and adjustability of the test (Balakrishnan N. \& Han D., 2009). For an accelerated simple step-stress life testing (ASSLT) the samples are subjected (usually) to a higher-than-normal stress for a pre-specified time, then the stress is elevated to a new stress (on those samples that did not fail in the first step) until the total time of the test is elapsed. The time of failures for failed samples are collected and analyzed.

Different censoring criteria for accelerated life testing are used in literature. Under Type-I censoring the test is allowed to run for a pre-specified time during which the failure times for the samples are recorded. Under Type-II censoring the test is allowed to run until a pre-specified number of failures are observed and the failure times recorded. A hybrid censoring criterion is also used in literature with accelerated step-life testing. Progressive Type-I right censoring is used to reduce the cost of the experimentation. In this censoring criterion a pre-specified 
number or proportion of test units are removed before their failure at each test step. Readers may refer to Gouno and Balakrishnan (2001) for more information in this area.

The optimal plan for accelerated step-stress life testing has gained great attention in the last three decades as the test provides more flexibility and adjustability than ALT. Nelson (1980) proposed the cumulative exposure model for step-stress ALT. He suggested that the failure distribution of the specimens in a step-stress test must be a collection of segments of the life distribution of each step. Bai and Kim (1993) designed a simple step-stress accelerated life test using Weibull life distribution and a log-linear relationship between the stress and the scale parameter using MLE approach. Escobar and Meeker (1995) developed a general plan for constant-stress ALT with multi experimental factors. Dorp et al. (1996) developed a Baye's approach for accelerated step-stress testing plan considering ramping. Khamis and Higgins (1998) proposed Khamis-Higgins model as a new Cumulative exposure model for accelerated step-stress testing. Abdulla and Shie (2002) extended the work done by Khamis and Higgins in 1998. The authors applied Khamis-Higgins model to the case of finding the optimal stress changing time for the simple step-stress ALT plan when the shape parameter is unknown. Gouno et al. (2004) discussed optimal accelerated step-stress life test under progressive type-I censoring under large sample size and small original sample size censoring proportion. Balakrishnan and Han (2008) proposed a simple step-stress model under type-II censoring with independent exponential life distribution for different risk factors using MLE. Balakrishnan and Han (2009) made a practical modification for the model discussed in Gunno et al. (2004) where small to medium sample size and survivals censoring proportion were used instead of original sample size censoring proportion under the assumption of equal step duration.

This paper discusses the design of the optimal ASSLT plan using Bayesian approach when large sample size and small censoring proportion are considered. An exponential life distribution and progressive Type-I right censoring are considered. Unlike Gouno et al. (2004) and Balakrishnan and Han (2009), the durations of the steps are not considered equal and the uncertainty in the model parameters will be considered through Bayesian statistics opposed to Gouno (2004) and Balakrishnan and Han (2009) where they used classical statistics under which the model parameters were considered fixed-unknown values. The Bayesian statistics will be used for the analysis as it incorporates the prior knowledge about the model parameters in the inference process while in the classical statistics prior knowledge about the model parameters cannot be used even if it available. The data collected under the accelerated conditions will be used to extrapolate the $p^{\text {th }}$ percentile of the life under normal operating conditions. The decision variables will be optimized using the expected variance for the $p^{\text {th }}$ percentile of the life under normal operating conditions as the objective function. The censoring proportion should be small enough to guarantee that the expected number of samples censored from the original sample size is less than the survival samples at the end of the first step.

\section{Model Description and Assumptions}

Tests under Type-I progressive censoring utilizes test resources more efficiently than traditional Type-I censoring as it allows for the removal of some samples during the test before their failure. Those samples can be used in other tests or even somewhere else in the facility. This means that the actual testing cost can be reduced significantly by using this censoring method. Utilizing progressive Type-I censoring with large sample size and small original sample censoring proportion, the ASSLT can be described as follows: $n$ samples are placed in the test under $x_{l}$ stress level (above normal stress level) for certain time, $\tau$, during which $n_{l}$ failures will be observed. At $\tau, c$ live samples will be removed from the test and the stress level will be elevated to a new value, $x_{2}$, on the remaining samples until the end of the test at total testing time $t_{t}$. Here, $\mathrm{c}=\mathrm{n} \times \pi$, where $\pi$ is the censoring proportion.

\subsection{Assumptions}

1. Two stress levels are used

2. Exponential life distribution is assumed in each steps

3. The mean time to failure $(M T T F)$ is assumes to have a log-linear function with the stress level $x_{i}$ such that

$$
\ln \left(\mathrm{MTTF}_{\mathrm{i}}\right)=\mathrm{a}+\mathrm{bxi}
$$

where $a$ and $b$ are two unknown parameters that depend on the product tested and the test method used.

4. The cumulative exposure model is assumed in which the remaining life of the samples depends only on the present amount of cumulative exposure.

5. Progressive Type-I right censoring will be used in which $\pi$ proportion of the original sample size will be removed at time $\tau$. 
6. The sample size, $n$, is large enough to guarantee that the number of survival samples in the first step is more than the number of progressively censored samples in that step.

\section{Simple Step Accelerated Life Test}

Applying the cumulative exposure model and the exponential life assumptions, the cumulative distribution function for the model can be given as:

$$
\mathrm{F}(\mathrm{t})= \begin{cases}1-\exp \left(-\frac{\mathrm{t}}{\mathrm{MTTF}}\right) & 0<\mathrm{t}<\tau \\ 1-\exp \left(-\frac{\mathrm{t}-\tau\left(1-\frac{\mathrm{MTTF}_{2}}{\mathrm{MTTF}_{1}}\right)}{\mathrm{MTTF}_{2}}\right) & \tau \leq \mathrm{t} \leq \mathrm{t}_{\mathrm{t}}\end{cases}
$$

where $\tau$ and $t_{t}$ are the stress changing time and the total test duration respectively. The corresponding probability distribution function can be given as:

$$
f(t)= \begin{cases}\frac{1}{M_{T T F}} \exp \left(-\frac{t}{M_{T T F}}\right) & 0<t<\tau \\ \frac{1}{M_{1 T F}} \exp \left(-\frac{t-\tau\left(1-\frac{M_{T T F_{2}}}{M_{T T F}}\right)}{M T T F_{2}}\right) & \tau \leq t \leq t_{t}\end{cases}
$$

Moreover, the reliability function at $t_{t}$ can be given as:

$$
R\left(t_{t}\right)=\exp \left(-\frac{t_{t}-\tau\left(1-\frac{M_{T T F_{2}}}{M_{T T F}}\right)}{M_{T T F}}\right) t \geq t_{t}
$$

and the reliability function, for the censored data, at $\tau$ can be given as:

\subsection{Bayesian Plan}

$$
\mathrm{R}(\tau)=\exp \left(-\frac{\tau}{\mathrm{MTTF}_{1}}\right)
$$

The fundamental differences between Bayesian approach and MLE approach are in the nature of the unobserved quantities. While in Bayesian approach the unobserved quantities are considered random variables with certain probability density (mass) function, in MLE approach they are considered fixed unknown quantities. In addition, the Bayesian approach permits the experimenter to integrate the prior knowledge about the unobserved quantities that are often used in the designing process while in the MLE approach the experimenter cannot use such prior knowledge even if it is very useful.

To start developing the Bayesian plan, let $\mathrm{MTTF}_{\mathrm{H}}$ be the MTTF at stress level $\mathrm{x}_{\mathrm{H}}$, which can be given by

$$
\mathrm{MTTF}_{\mathrm{H}}=\exp \left(a+b \mathrm{x}_{\mathrm{H}}\right)
$$

and let MTTF $_{L}$ be the MTTF at stress level $x_{L}$ which can be given by

$$
\operatorname{MTTF}_{\mathrm{L}}=\exp \left(a+b \mathrm{x}_{\mathrm{L}}\right)
$$

where $\mathrm{X}_{\mathrm{H}}$ and $\mathrm{X}_{\mathrm{L}}$ are stress levels applied on step 2 and step 1, respectively.

Joint prior distribution on $\mathrm{MTTF}_{\mathrm{H}}$ and $\mathrm{MTTF}_{\mathrm{L}}$ will be assigned instead of assigning joint prior distribution directly to $a$ and $b$ as little information about the values of $a$ and $b$ are usually available, while more information about the values of $\mathrm{MTTF}_{\mathrm{H}}$ and $\mathrm{MTTF}_{\mathrm{L}}$ are usually available and might be taken from previous experience. Hence, if the experimenter wants to specify a joint prior distribution directly to $a$ and $b$, a very non-informative priors for them should be used (since little information is available about $a$ and $b$ which in turn introduces a lot of unwanted noises in the simulation process and eliminates the purpose of using Bayesian method. Once the joint prior distribution on $\mathrm{MTTF}_{\mathrm{H}}$ and $\mathrm{MTTF}_{\mathrm{L}}$ are specified, bivariate random variables transformation can be applied to get the joint prior distribution of $a$ and $b$.

Employing Baye's theorem, the posterior distribution of the model parameters can be derived given the data $t$ as 


$$
f(a, b \mid t)=\frac{f(t \mid a, b) f(a, b)}{f(t)}
$$

where $f(t \mid a, b)$ is the likelihood of the data and $f(t)=\iint f(t \mid a, b) f(a, b)$ dadb is the preposterior marginal distribution of $t$. Using bivariate random variables transformation $\mathrm{f}(a, b)$ can be derived from the joint priors distributions of $\mathrm{MTTF}_{\mathrm{H}}$ and $\mathrm{MTTF}_{\mathrm{L}}$. The joint prior distribution of $a$ and $b$ can be expressed by

$$
\mathrm{f}(\mathrm{a}, \mathrm{b})=\mathrm{f}\left(\mathrm{a}\left(\mathrm{MTTF}_{\mathrm{H}}, \mathrm{MTTF}_{\mathrm{L}}\right), \mathrm{b}\left(\mathrm{MTTF}_{\mathrm{H}}, \mathrm{MTTF}_{\mathrm{L}}\right)\right) \times \mathrm{abs}|\mathrm{J}|
$$

Where $a\left(M_{T T F}, M_{T T F}\right)$ and $b\left(M_{T T F}, M T T F_{L}\right)$ given by

$$
\begin{gathered}
\mathrm{a}\left(\mathrm{MTTF}_{\mathrm{H}}, \mathrm{MTTF}_{\mathrm{L}}\right)=\ln \left(\mathrm{MTTF}_{\mathrm{H}}\right)-\mathrm{bX}_{\mathrm{H}} \\
\mathrm{b}\left(\mathrm{MTTF}_{\mathrm{H}}, \mathrm{MTTF}_{\mathrm{L}}\right)=\frac{\ln \left(\mathrm{MTTF}_{\mathrm{H}}\right)-\ln \left(\mathrm{MTTF}_{\mathrm{L}}\right)}{\left(\mathrm{X}_{\mathrm{H}}-\mathrm{X}_{\mathrm{L}}\right)}
\end{gathered}
$$

And $\mathrm{J}$ is the Jacoubian matrix given by

$$
J=\left[\begin{array}{ll}
\frac{\partial \mathrm{MTTF}_{H}}{\partial \mathrm{a}} & \frac{\partial \mathrm{MTTF}_{H}}{\partial \mathrm{b}} \\
\frac{\partial \mathrm{MTTF}_{\mathrm{L}}}{\partial \mathrm{a}} & \frac{\partial \mathrm{MTTF}_{\mathrm{L}}}{\partial \mathrm{b}}
\end{array}\right]=\left[\begin{array}{ll}
\exp \left(\mathrm{a}+\mathrm{b} \mathrm{X}_{\mathrm{H}}\right) \mathrm{X}_{\mathrm{H}} \exp \left(\mathrm{a}+\mathrm{b} \mathrm{X}_{\mathrm{H}}\right) \\
\exp \left(\mathrm{a}+\mathrm{b} \mathrm{X}_{\mathrm{L}}\right) \mathrm{X}_{\mathrm{L}} \exp \left(\mathrm{a}+\mathrm{b} \mathrm{X}_{\mathrm{L}}\right)
\end{array}\right]
$$

By substituting equations (10), (11), and (12) into equation (9), the joint prior distribution of $a$ and $b$ as a function of $\mathrm{MTTF}_{\mathrm{H}}$ and $\mathrm{MTTF}_{\mathrm{L}}$ can be given by

$$
f(a, b)=f\left(\ln \left(M_{T T F}\right)-b X_{H}, \frac{\ln \left(M T T F_{H}\right)-\ln \left(M_{T T F}\right)}{\left(X_{H}-X_{L}\right)}\right) \times a b s \mid\left[\begin{array}{l}
\exp \left(a+b X_{H}\right) X_{H} \exp \left(a+b X_{H}\right) \\
\exp \left(a+b X_{L}\right) X_{L} \exp \left(a+b X_{L}\right)
\end{array}\right]
$$

Given the data $\boldsymbol{t}$, the posterior inference on a model parameter such as $a, b$ or a function of the model parameters such as $\mathrm{t}_{\mathrm{p}}\left(\mathrm{x}_{0}\right)$ is based on its marginal posterior distribution.

The mean and variance of $\mathrm{t}_{\mathrm{p}}\left(\mathrm{x}_{0}\right)$ at given $\boldsymbol{t}$ can be calculated, respectively, as follows

$$
E\left(t_{p}\left(x_{0}\right) \mid t\right)=\iint t_{p}\left(x_{0}\right) f(a, b \mid t) d a d b
$$

and

$$
\operatorname{Var}\left[\mathrm{t}_{\mathrm{p}}\left(\mathrm{x}_{0}\right) \mid \mathrm{t}\right]=\iint\left(\mathrm{t}_{\mathrm{p}}\left(\mathrm{x}_{0}\right)-\mathrm{E}\left(\mathrm{t}_{\mathrm{p}}\left(\mathrm{x}_{0}\right) \mid \mathrm{t}\right)\right)^{2} \mathrm{f}(\mathrm{a}, \mathrm{b} \mid \mathrm{t}) \mathrm{dadb}
$$

Hence, the pre-posterior variance of $t_{p}\left(x_{0}\right)$ can be calculated as

$$
\operatorname{Et} \operatorname{Var}\left[\mathrm{t}_{\mathrm{p}}\left(\mathrm{x}_{0}\right) \mid \mathrm{t}\right]=\int_{0}^{\infty} \operatorname{Var}\left[\mathrm{t}_{\mathrm{p}}\left(\mathrm{x}_{0}\right) \mid \mathrm{t}\right] \mathrm{f}(\mathrm{t}) \mathrm{dt}
$$

The pre-posterior variance given by equation (16) can be used as the objective function for optimizing the test as it doesn't depend on $\boldsymbol{t}$.

The solution will utilize the Gibbs Sampling that is built in WINBUGS (A stand-alone program to allow practical MCMC methods available to applied statisticians) (Spiegelhalter D., Thomas A., Best N., \& Lunn, D., 2003). At each iteration of the Gibbs sampling a value for $\mathrm{MTTF}_{\mathrm{H}}$ and $\mathrm{MTTF}_{\mathrm{L}}$ is drawn from their joint prior distribution and a value of $a$ and $b$ will be calculated using equations (10) and (11) respectively. Based on the calculated values of $a$ and $b$ a value for $\overline{\mathrm{t}}\left(\mathrm{x}_{0}\right)$ is computed by

$$
\ln \left(\overline{\mathrm{t}_{\mathrm{p}}}\right)=-(\ln (\ln (1-\mathrm{p}))+\mathrm{a}+\mathrm{bx} 0)
$$

As the number of sampled points increases, the distribution for the calculated points for $\overline{\mathrm{t}_{\mathrm{p}}}\left(\mathrm{x}_{0}\right)$ can be regarded as an approximation for the distribution of $\mathrm{t}_{\mathrm{p}}\left(\mathrm{x}_{0}\right)$. The variance of $\mathrm{t}_{\mathrm{p}}\left(\mathrm{x}_{0}\right)$ distribution, $\operatorname{Var}\left[\mathrm{t}_{\mathrm{p}}\left(\mathrm{x}_{0}\right) \mid \mathrm{t}\right]$, can be approximated simply by calculating the variance of $\overline{\mathrm{t}_{\mathrm{p}}}\left(\mathrm{x}_{0}\right)$. If the above process is repeated many times and the average of $\operatorname{Var}\left[\overline{\mathrm{t}_{\mathrm{p}}}\left(\mathrm{x}_{0}\right) \mid \mathrm{t}\right]$ is taken, which is $\operatorname{Et}\left[\operatorname{Var}\left[\overline{\mathrm{t}_{\mathrm{p}}}\left(\mathrm{x}_{0}\right) \mid \mathrm{t}\right]\right]$ this average can be regarded as an estimation for the expected variance of $t_{p}\left(x_{0}\right)$ which is $\operatorname{Et}\left[\operatorname{Var}\left[t_{p}\left(x_{0}\right) \mid t\right]\right]$ that is given by equation (16).

Because the model consists of two steps and two censoring times, the horizon for the likelihood function will be split into four parts, the likelihood function can be given by: 


$$
\mathrm{L}=\mathrm{f}(\mathrm{t} \mid \mathrm{a}, \mathrm{b})=\left(\lambda_{1}^{\mathrm{n}_{1}} \exp \sum_{\mathrm{i}=1}^{\mathrm{n}_{1}}\left(-\lambda_{1} \mathrm{t}_{\mathrm{i}}\right)\right)\left(\exp \sum_{\mathrm{i}=1}^{\mathrm{c}}\left(-\lambda_{1} \tau\right)\right)\left(\lambda_{2}^{\mathrm{n}_{2}} \exp \sum_{\mathrm{i}=1}^{\mathrm{n}_{2}}\left(-\lambda_{2} \mathrm{t}_{\mathrm{i}}+\tau\left(\lambda_{2}-\lambda_{1}\right)\right)\left(\exp \sum_{\mathrm{i}=1}^{\mathrm{N}-\mathrm{n}_{1}-\mathrm{n}_{2}-\mathrm{c}}\left(-\lambda_{2} \mathrm{t}_{\mathrm{t}}+\tau\left(\lambda_{2}-\lambda_{1}\right)\right)\right)\right.
$$

where $\lambda_{\mathrm{i}}=\frac{1}{\mathrm{MTTF}_{\mathrm{i}}}$ for $i=1,2$ corresponding to the first and the second steps respectively.

Substituting $\lambda_{\mathrm{i}}=\exp (-\mathrm{a}-\mathrm{bx})$ into equation (18), the likelihood function given the model parameters, $a$ and $b$, can be written as:

$$
\begin{aligned}
& \mathrm{L}=\left(\exp \left(-\mathrm{a}-\mathrm{bx}_{1}\right)^{\mathrm{n}_{1}} \exp \sum_{\mathrm{i}=1}^{\mathrm{n}_{1}}\left(-\exp \left(-\mathrm{a}-\mathrm{bx}_{1}\right) \mathrm{t}_{\mathrm{i}}\right)\right) \times\left(\exp \sum_{\mathrm{i}=1}^{\mathrm{c}}\left(-\exp \left(-\mathrm{a}-\mathrm{bx}_{1}\right) \tau\right)\right) \\
& \times\left(\exp \left(-\mathrm{a}-\mathrm{bx}_{2}\right)^{\mathrm{n}_{2}} \exp \sum_{\mathrm{i}=1}^{\mathrm{n}_{2}}\left(-\exp \left(-\mathrm{a}-\mathrm{bx}_{2}\right) \mathrm{t}_{\mathrm{i}}+\tau\left(\exp \left(-\mathrm{a}-\mathrm{bx} \mathrm{x}_{2}\right)-\exp \left(-\mathrm{a}-\mathrm{bx}_{1}\right)\right)\right)\right) \\
& \times\left(\exp \sum_{\mathrm{i}=1}^{\mathrm{N}-\mathrm{n}_{1}-\mathrm{n}_{2}-\mathrm{c}}\left(-\exp \left(-\mathrm{a}-\mathrm{bx}_{2}\right) \mathrm{t}_{\mathrm{t}}+\tau\left(\exp \left(-\mathrm{a}-\mathrm{bx}_{2}\right)-\exp \left(-\mathrm{a}-\mathrm{bx}_{1}\right)\right)\right)\right)
\end{aligned}
$$

The likelihood function of the model for one data point can be written by:

$$
\begin{aligned}
& \mathrm{L}=\mathrm{I}_{1} \mathrm{I}_{2}\left(1-\mathrm{I}_{3}\right)\left(\exp \left(-\mathrm{a}-\mathrm{bx}_{1}\right) \exp \left(-\exp \left(-\mathrm{a}-\mathrm{bx}_{1}\right) \mathrm{t}\right)\right) \mathrm{I}_{1} \mathrm{I}_{2} \mathrm{I}_{3} \exp \left(-\exp \left(-\mathrm{a}-\mathrm{bx}_{1}\right) \tau\right) \\
& \left.\mathrm{I}_{2}\left(1-\mathrm{I}_{1}\right)\left(\exp \left(-\mathrm{a}-\mathrm{bx}_{2}\right) \exp \left(-\exp \left(-\mathrm{a}-\mathrm{bx}_{2}\right) \mathrm{t}\right)+\tau\left(\exp \left(-\mathrm{a}-\mathrm{bx}_{2}\right)-\exp \left(-\mathrm{a}-\mathrm{bx}_{1}\right)\right)\right)\right) \\
& \left(1-\mathrm{I}_{2}\right)\left(\exp \left(-\exp \left(-\mathrm{a}-\mathrm{bx}_{2}\right) \mathrm{t}_{\mathrm{t}}+\tau\left(\exp \left(-\mathrm{a}-\mathrm{bx}_{2}\right)-\exp \left(-\mathrm{a}-\mathrm{bx}_{1}\right)\right)\right)\right)
\end{aligned}
$$

Where $\mathrm{I}_{1}, \mathrm{I}_{2}$ and $\mathrm{I}_{3}$ given by

$$
\begin{aligned}
& I_{1}= \begin{cases}1 & \text { if } t \leq \tau \\
0 & \text { if } t>\tau\end{cases} \\
& I_{2}=\left\{\begin{array}{ll}
1 & \text { if } t \leq t_{t} \\
0 & \text { if } t>t_{t}
\end{array}\right. \text { and } \\
& I_{3}= \begin{cases}1 & \text { if } t=\tau \\
0 & \text { if } t \neq \tau\end{cases}
\end{aligned}
$$

respectively.

Based on the above analysis, the model can be given as

$$
\min \operatorname{Et}\left[\operatorname{Var}\left[\mathrm{t}_{\mathrm{p}}\left(\mathrm{x}_{0}\right) \mid \mathrm{t}\right]\right]
$$

s.t.

$$
\begin{aligned}
& \tau<\mathrm{t}_{\mathrm{t}}, \\
& \mathrm{x}_{0}<\mathrm{x}_{1}<\mathrm{x}_{2}, \\
& \mathrm{E}\left[\mathrm{n}_{1}\right] \ll \mathrm{n}(1-\pi) \\
& \mathrm{x}_{1}, \tau>0
\end{aligned}
$$

where $E\left[n_{1}\right]$ is the expected number of failures at step 1, which can be calculated as

$$
\mathrm{E}\left[\mathrm{n}_{1}\right]=\mathrm{n} \times \iint \mathrm{F}_{1}(\tau \mid \mathrm{a}, \mathrm{b}) \mathrm{f}(\mathrm{a}, \mathrm{b}) \mathrm{dadb}
$$

and $E\left[n_{2}\right]$ is the expected number of failures at step 2. It can be calculated as:

$$
E\left[n_{2}\right]=\left(n(1-\pi)-E\left[n_{1}\right]\right) \times \iint F_{2}\left(t_{t} \mid a, b\right) f(a, b) d a d b
$$

The constraint $E\left[n_{1}\right] \ll n(1-\pi)$ ensures that the assumption number 6 is guaranteed.

\section{Numerical Examples and Analysis}

Two examples will be given, in each example two cases will be illustrated, case 1 will use informative priors and case 2 will use less informative priors for $\mathrm{MTTF}_{\mathrm{H}}$ and $\mathrm{MTTF}_{\mathrm{L}}$. In each case three different censoring proportions will be considered, $\pi=\{0,0.05,0.1\}, \pi=0$ represents the conventional Type-I censoring scenario. The other two values of $\pi$ represent progressive Type-I right censoring. 


\subsection{Example 1}

The following assumptions and values are used in this example:

1) Total testing time $t_{t}=900000$ seconds

2) Normal stress level $x_{0}=1.5$ volts

3) High stress level $x_{2}=6.5$ volts

4) Sample size $\mathrm{n}=500$ samples

5) Discretize the sample space of the decision variables, $\tau$ and $x_{1}$ into 40 points each to form 1600 combination of decision variables. Discretizing the sample space helps in reducing the sample space size into a manageable size that can be used in exhaustive search method optimization.

1. $\mathrm{MTTF}_{\mathrm{H}}$ and $\mathrm{MTTF}_{\mathrm{L}}$ are considered independent with uniform prior distributions given in Table 1.

\subsubsection{Case 1}

The informative priors will be used in this case. Table 2, shows the optimal solutions found by the model for the three different values of $\boldsymbol{\pi}$. For $\pi=0$, the optimal solution found was $\tau=808430.7$ seconds and $x_{1}=5.2$ volts with $\mathrm{E}_{\mathrm{t}}\left[\operatorname{Var}\left[\mathrm{t}_{\mathrm{p}}\left(\mathrm{x}_{0}\right) \mid \mathrm{t}\right]\right]=2.50 \mathrm{E} 15$ second $^{2}$. Apparently, from the table, as $\pi$ increases the $\mathrm{E}_{\mathrm{t}}\left[\operatorname{Var}\left[\mathrm{t}_{\mathrm{p}}\left(\mathrm{x}_{0}\right) \mid \mathrm{t}\right]\right]$ increases and, consequently, the precision for the test decreases.

Let \%EVar be the percentage change in $\mathrm{E}_{t}\left[\operatorname{Var}\left[\mathrm{t}_{\mathrm{p}}\left(\mathrm{x}_{0}\right) \mid \mathrm{t}\right]\right]$ due to the change in censoring proportion $\pi$, \%EVar can be calculated as

$$
\% \operatorname{EVar}_{\mathrm{i}}=\frac{\mathrm{E}_{\mathrm{t}}\left[\operatorname{Var}\left[\mathrm{t}_{\mathrm{p}}\left(\mathrm{x}_{0}\right) \mid \mathrm{t}, \pi_{0}\right]\right]-\mathrm{E}_{\mathrm{t}}\left[\operatorname{Var}\left[\mathrm{t}_{\mathrm{p}}\left(\mathrm{x}_{0}\right) \mid \mathrm{t}, \pi_{\mathrm{i}}\right]\right]}{\mathrm{E}_{\mathrm{t}}\left[\operatorname{Var}\left[\mathrm{t}_{\mathrm{p}}\left(\mathrm{x}_{0}\right) \mid \mathrm{t}, \pi_{0}\right]\right]} \times 100 \%
$$

where $i=1,2$ corresponds to $\pi=0.05$ and $\pi=0.1$ respectively. It is obvious from Table 3 that as $\pi$ increases the $\%$ EVar increases. The increase in $\pi$ reduces the number of samples available for the second step. The test responded to this reduction by decreasing $\tau$ and increasing the time available for the second step, $t_{2}$.

The decrease in $\tau$ increases $t_{2}$, which in turns, forces the test to have more failures in the second step (low quality failures) and less failures in the first step (high quality failures). Failures in the second step contain small amount of information about $t_{p}$ as they need high degree of extrapolation between the high stress level in step 2 and the normal operating stress level $\mathrm{x}_{0}$, therefore, they can be seen as a low quality failures while failures happened in the first step can be seen as a high quality failures relative to the failures happened in the second step as they need less extrapolation. Using equations (2) and (3), the expected numbers of failures for the first and second steps can be given as shown in Table 4. It is clear that as $\pi$ increases $E\left[n_{1}\right]$ reduces, $E\left[n_{2}\right]$ increases, and the expected total failures in the test increases. The reduction in $E\left[n_{1}\right]$ and the increase in $E\left[n_{2}\right]$ force $\mathrm{E}_{\mathrm{t}}\left[\operatorname{Var}\left[\mathrm{t}_{\mathrm{p}}\left(\mathrm{x}_{0}\right) \mid \mathrm{t}\right]\right]$ to increase.

\subsubsection{Case 2}

The non-informative priors were used in this case, Table 5 shows the results for this case. The same trend found in the first case also found in this case. $\operatorname{The} \mathrm{E}_{\mathrm{t}}\left[\operatorname{Var}\left[\mathrm{t}_{\mathrm{p}}(\mathrm{x} 0) \mid \mathrm{t}\right]\right]$ increases as $\pi$ increases and, consequently, the precision of the test decreases.

Table 6 shows the same trend found in Table 3, the \%EVar and $t_{2}$ both increase with increasing the value of $\pi$.

Table 7 shows the same trend found in Table 4 , as $\pi$ increases $E\left[n_{1}\right]$ decreases, $E\left[n_{2}\right]$ increases and the expected total failures in the test increase. It is clear also here that the reduction in $E\left[n_{1}\right]$ and the increase in $E\left[n_{2}\right]$ force $\mathrm{E}_{\mathrm{t}}\left[\operatorname{Var}\left[\mathrm{t}_{\mathrm{p}}\left(\mathrm{x}_{0}\right) \mid \mathrm{t}\right]\right]$ to increase.

One interesting observation in this table is that even though the $E\left[n_{2}\right]$ for $\pi=0.05$ is 7.4 less than the $E\left[n_{2}\right]$ for $\pi$ $=0.1$ and the $\mathrm{E}\left[\mathrm{n}_{1}\right]$ for $\pi=0.05$ is 0.3 more than the $\mathrm{E}\left[\mathrm{n}_{1}\right]$ for $\pi=0.1$, the $\mathrm{E}_{\mathrm{t}}\left[\operatorname{Var}\left[\mathrm{t}_{\mathrm{p}}(\mathrm{x} 0) \mid \mathrm{t}\right]\right]$ for $\pi=0.05$ is about $4.2 \%$ less than the $\mathrm{E}_{\mathrm{t}}\left[\operatorname{Var}\left[\mathrm{t}_{\mathrm{p}}\left(\mathrm{x}_{0}\right) \mid \mathrm{t}\right]\right]$ for $\pi=0.1$. This indicates that a failure in the first step contains more information about $t_{p}\left(x_{o}\right)$ than a failure in the second step. This is so because the failure at the first step happens 
on a lower stress level than a failure on the second step and the extrapolation from the low stress to the normal stress condition is more precise than the extrapolation from the high stress, therefore, the $E_{t}\left[\operatorname{Var}\left[t_{p}\left(x_{0}\right) \mid t\right]\right]$ increased for $\pi=0.1$.

Comparing the results for case 1 and case 2 , one can see that \%EVar was always higher in case 2 than in case 1 for the different values of $\boldsymbol{\pi}$, therefore, the effect of progressive censoring in reducing the test precision was more obvious in case 2. To understand this, one should remember that the information about $t_{p}\left(\mathrm{x}_{\mathrm{o}}\right)$ comes from two sources, which are the information contained in the priors and the information contained in the data. In case 2, the information contained in the priors about $t_{p}\left(x_{o}\right)$ is negligible compared to the information contained in the data since weak priors were used. In case 1 , the information contained in the data is negligible compared to the information contained in the priors since strong priors were used. This means that the data (mainly failures in first step as was discussed in the previous paragraph) is more important when the priors are non- informative than when the priors are informative. But when comparing tables (4) and (7) it is obvious that $\mathrm{E}\left[\mathrm{n}_{1}\right]$ for case 2 is always less than $E\left[n_{1}\right]$ for case 1,consequently, the value of\%EVar is always higher in case 2 than in case 1 . This means that tests with weak priors are affected more by progressive censoring than tests with strong priors.

\subsection{Example 2}

The following assumptions and values are used in this example:

1) Total testing time $t_{t}=1900$ seconds.

2) Normal stress level $x_{0}=1.5$ volts.

3) High stress level $x_{2}=7$ volts.

4) Sample size $\mathrm{n}=500$ samples.

5) Discretize the sample space of the decision variables, $\tau$ and $x_{1}$ into 40 points each to form 1600 combination of decision variables.

6) $\mathrm{MTTF}_{\mathrm{H}}$ and $\mathrm{MTTF}_{\mathrm{L}}$ are considered independent with uniform prior distributions given by Table 8.

Table 9 summarizes the results for the two cases in this example. The same trend found in example 1 is also found in this example. The $\mathrm{E}_{\mathrm{t}}\left[\operatorname{Var}\left[\mathrm{t}_{\mathrm{p}}\left(\mathrm{x}_{0}\right) \mid \mathrm{t}\right]\right], \% \mathrm{EVar}, \mathrm{E}\left[\mathrm{n}_{2}\right]$, and total expected number of failures are all increase as $\pi$ increases while $E\left[n_{1}\right]$ decreases as $\pi$ increases. Also the effect of progressive censoring is more obvious in case 2 than in case 1 as the \%EVar is higher in case 2 than in case 1 for this example too.

\section{Conclusions}

Example 1 and example 2 showed consistent results. Based on those examples it is obvious that at the same censoring proportion, as the priors become more informative, the precision of the test increases. This is expected because as the priors become more informative the amount of information contained in those priors about the model parameters increases and thus the variance of $t_{p}$ decreases.

The results showed that for the same priors, the smaller the censoring proportion, the higher the precision of the test is. This is true since for smaller censoring proportions there will be more samples available in the second step as the progressively censored-samples will be less.

As the stress level increases, the information contained in the failed sample about $t_{p}$ decreases as more extrapolation will be needed between the stress level used and the normal stress level at which $t_{p}$ will be evaluated. Therefore, a failure in the first step can be seen as a higher quality failure than a failure in the second step.

The effect of using informative priors was obvious in the results, it is clear that as the priors become more informative, the effect of progressive censoring on the test precision becomes less apparent as most of the information about $t_{p}$ comes from the priors not from the data (failures). Therefore, reducing number of samples used in the second step as results of progressive censoring will have minor effect on the test precision. This means that the test becomes less sensitive to the censoring proportion as the priors become more informative.

\section{Recommendations}

Using the progressive censoring is recommended in the case of available strong priors. In this case the test precision will not be affected significantly, and at the same time, the cost of the test will be reduced. 


\section{Acknowledgment}

The author is grateful to the Applied Science Private University, Amman, Jordan, for the financial support granted to this research (Grant No. DRGS-2011-43).

\section{References}

Abdullah, A., \& Shie, Y. (2002). Optimal Simple Step-Stress Plan for Khamis-Higgins Model. IEEE Transactions on Reliability, 51(2), 212-215. http://dx.doi.org/10.1109/TR.2002.1011527

Balakrishnan, N., \& Han, D. (2008). Exact inference for a simple step-stress model with competing risks for failure from exponential distribution under Type-II censoring. Journal of Statistics Planning and Inference, 138, 4172-4186. http://dx.doi.org/10.1016/j.jspi.2008.03.036

Balakrishnan, N., \& Han, D. (2009). Optimal Step-Stress Testing for Progressive Type-I Censored Data from Exponential Distribution. Journal of Statistical Planning and Inference, 139, 1782-1798. http://dx.doi.org/10.1016/j.jspi.2008.05.030

Bai, D., \& Kim, M. (1993). Optimum Simple Step-Stress Accelerated Life tests for Weibull Distribution and Type I Censoring. Naval Research Logistics, Vol. 40, $193-210$. http://dx.doi.org/10.1002/1520-6750(199303)40:2<193::AID-NAV3220400205>3.0.CO;2-J

Dorp, V. (1996). Step-Stress Accelerated Life Testing. IEEE Transactions on Reliability, 45(3), $491-498$. http://dx.doi.org/10.1109/24.537021

Escobar, L., \& Meeker, W. (1995). Planning Accelerated Life Tests with Two or More Experimental factors. Technometrics, 37(4), 411-427. http://dx.doi.org/10.2307/1269733

Gouno, E., \& Balakrishnan, N. (2001). Step-stress accelerated life test. In Handbook of Statistics-20: Advances in Reliability (Eds., N. Balakrishnan and C. R. Rao), 623-639, North-Holland, Amsterdam.

Gouno, E., Sen, A., \& Balakrishnan, N. (2004). Optimal Step-Stress Test Under Progressive Type-I Censoring. IEEE Transactions on Reliability, 53, 383-393. http://dx.doi.org/10.1109/TR.2004.833320

Khamis, I. H., \& Higgins, J. J. (1998). A new model for step-stress testing. IEEE Transactions on Reliability, 47, 131-134. http://dx.doi.org/10.1109/24.722275

Meeker, W. Q., \& Escobar, L. A. (1998). Statistical Methods for Reliability Data, New York, John Wiley \& Sons.

Nelson, W. B. (1980). Accelerated life testing step-stress models and data analysis. IEEE Trans. Reliability., R-29, 103-108. http://dx.doi.org/10.1109/TR.1980.5220742

Nelson, W. (1990). Accelerated Testing: Statistical Models, Test Plans, and Data Analyses, New York, John Wiley \& Sons.

Spiegelhalter, D., Thomas, A., Best, N., \& Lunn, D. (2003). WinBUGS User Manual. [Online] Available: http:/www.mrc-bsu.cam.ac.uk/bugs/winbugs/contents.shtml

Table1. Prior distributions used in example 1

\begin{tabular}{lll}
\hline Prior & MTTFH $\mid\left(x_{H}=7\right)$ & MTTF $_{L} \mid\left(x_{L}=3\right)$ \\
\hline Informative & $\mathrm{U}(59800,59948)$ & $\mathrm{U}(178482000,178482602)$ \\
Less informative & $\mathrm{U}(59000.60674)$ & $\mathrm{U}(178400000,178564602)$ \\
\hline
\end{tabular}

Table2. Optimal plans for case 1

\begin{tabular}{llll}
\hline$\pi$ & $\tau$ & $x$ & $\mathrm{E}_{\mathrm{t}}\left[\operatorname{Var}\left[\mathrm{t}_{\mathrm{p}}\left(\mathrm{x}_{0}\right) \mid \mathrm{t}\right]\right]$ \\
\hline 0 & 808430.7 & 5.199359 & $2.5032 \mathrm{E}+15$ \\
0.05 & 785538.4 & 5.071795 & $2.54308 \mathrm{E}+15$ \\
0.1 & 762646.1 & 5.071795 & $2.568 \mathrm{E}+15$ \\
\hline
\end{tabular}

Table 3. Optimal plans along with the \%EVar for case 1

\begin{tabular}{cccc|cc}
\hline$\pi$ & $\tau$ & $x$ & $\mathrm{E}_{\mathrm{t}}\left[\operatorname{Var}\left[\mathrm{t}_{\mathrm{p}}\left(\mathrm{x}_{0}\right) \mid \mathrm{t}\right]\right]$ & $\% \mathrm{EVar}$ & $t_{2}$ \\
\hline 0.00 & 808430.7 & 5.199359 & $2.5032 \mathrm{E}+15$ & - & 91569.25321 \\
0.05 & 785538.4 & 5.071795 & $2.54308 \mathrm{E}+15$ & $1.57 \%$ & 114461.5603 \\
0.10 & 762646.1 & 5.071795 & $2.568 \mathrm{E}+15$ & $2.52 \%$ & 137353.8673 \\
\hline
\end{tabular}


Table 4. Expected number of failures in the first step and in the second step for case 1

\begin{tabular}{ccccccc}
\hline$\pi$ & $\tau$ & $x$ & $\mathrm{E}_{\mathrm{t}}\left[\operatorname{Var}\left[\mathrm{t}_{\mathrm{p}}(\mathrm{x} 0) \mid \mathrm{t}\right]\right]$ & $\mathrm{E}\left[\mathrm{n}_{1}\right]$ & $\mathrm{E}\left[\mathrm{n}_{2}\right]$ & Expected total failures \\
\hline 0 & 808430.7 & 5.199359 & $2.5032 \mathrm{E}+15$ & 23.7 & 64.8 & 88.5 \\
0.05 & 785538.4 & 5.071795 & $2.54308 \mathrm{E}+15$ & 14.7 & 76.4 & 91.1 \\
0.1 & 762646.1 & 5.071795 & $2.568 \mathrm{E}+15$ & 13.9 & 86.2 & 100.1 \\
\hline
\end{tabular}

Table 5. Optimal plans for case 2

\begin{tabular}{cccc}
\hline $\boldsymbol{\pi}$ & $\boldsymbol{\tau}$ & $\mathbf{x}$ & $\mathrm{Et}_{\mathrm{t}}\left[\operatorname{Var}\left[\mathrm{t}_{\mathrm{p}}(\mathrm{x} 0) \mid \mathrm{t}\right]\right]$ \\
\hline 0 & 762646.1 & 5.071795 & $2.3345 \mathrm{E}+16$ \\
0.05 & 739753.8 & 4.816667 & $2.46599 \mathrm{E}+16$ \\
0.1 & 716861.5 & 4.816667 & $2.56998 \mathrm{E}+16$ \\
\hline
\end{tabular}

Table 6. Optimal plans along with the \%EVar for case 2

\begin{tabular}{cccccc}
\hline$\pi$ & $\tau$ & $\mathrm{x}$ & $\mathrm{Et}\left[\operatorname{Var}\left[\mathrm{t}_{\mathrm{p}}\left(\mathrm{x}_{0}\right) \mid \mathrm{t}\right]\right]$ & $\% \mathrm{EVar}$ & $t_{2}$ \\
\hline 0 & 762646.1 & 5.071795 & $2.3345 \mathrm{E}+16$ & - & 137353.8673 \\
0.05 & 739753.8 & 4.816667 & $2.46599 \mathrm{E}+16$ & $5.33 \%$ & 160246.1744 \\
0.1 & 716861.5 & 4.816667 & $2.56998 \mathrm{E}+16$ & $9.16 \%$ & 183138.4814 \\
\hline
\end{tabular}

Table 7. Expected number of failures in the first step and in the second step for case 2

\begin{tabular}{ccccccc}
\hline $\boldsymbol{\pi}$ & $\boldsymbol{\tau}$ & $\mathbf{x}$ & $\mathrm{Et}_{\mathrm{t}}\left[\operatorname{Var}\left[\mathrm{t}_{\mathrm{p}}(\mathrm{x} 0) \mid \mathrm{t}\right]\right]$ & $\mathrm{E}\left[\mathrm{n}_{1}\right]$ & $\mathrm{E}\left[\mathrm{n}_{2}\right]$ & Expected total failures \\
\hline 0 & 762646.1 & 5.071795 & $2.3345 \mathrm{E}+16$ & 13.9 & 96.0 & 110.0 \\
0.05 & 739753.8 & 4.816667 & $2.46599 \mathrm{E}+16$ & 5.3 & 103.9 & 109.1 \\
0.1 & 716861.5 & 4.816667 & $2.56998 \mathrm{E}+16$ & 5.0 & 111.3 & 116.3 \\
\hline
\end{tabular}

Table 8. Prior distributions used in example 2

\begin{tabular}{ccc}
\hline Prior & $\mathrm{MTTF}_{\mathrm{H}} \mid\left(\mathrm{x}_{\mathrm{H}}=7\right)$ & $\mathrm{MTTF}_{\mathrm{L}} \mid\left(\mathrm{x}_{\mathrm{L}}=3\right)$ \\
\hline Informative & $\mathrm{U}(140.8,156.8)$ & $\mathrm{U}(8093,8113)$ \\
Less informative & $\mathrm{U}(100,196.8)$ & $\mathrm{U}(7900,8303)$ \\
\hline
\end{tabular}

Table 9. Summary of results for example 2

\begin{tabular}{ccccccccc}
\hline Prior & $\pi$ & $\tau$ & $x$ & $\mathrm{Et}\left[\operatorname{Var}\left[\mathrm{t}_{\mathrm{p}}(\mathrm{x} 0) \mid \mathrm{t}\right]\right]$ & $\mathrm{E}\left[\mathrm{n}_{1}\right]$ & $\mathrm{E}\left[\mathrm{n}_{2}\right]$ & $\begin{array}{c}\text { Total } \\
\text { expected } \\
\text { failures }\end{array}$ & $\% \mathrm{EVar}$ \\
\hline \multirow{3}{*}{ Informative } & 0.00 & 1803.3 & 3.605769 & 146359 & 28.0 & 74.2 & 102.2 & - \\
& 0.05 & 1755.0 & 3.605769 & 148898 & 26.8 & 101.0 & 127.8 & $1.71 \%$ \\
& 0.10 & 1706.7 & 3.465385 & 151050 & 20.3 & 122.0 & 142.3 & $3.11 \%$ \\
\hline \hline \multirow{3}{*}{ Non-informative } & 0.00 & 1658.3 & 3.465385 & 259603 & 19.3 & 158.4 & 177.7 & - \\
& 0.05 & 1610.0 & 3.32500 & 275698 & 14.5 & 170.1 & 184.6 & $5.84 \%$ \\
& 0.10 & 1561.7 & 3.184615 & 289483 & 10.7 & 176.0 & 186.7 & $10.32 \%$ \\
\hline
\end{tabular}

